\title{
ECONOMETRIC MODEL FOR ESTIMATION OF HEAVY METALS IN WILD EDIBLE MUSHROOM (SUILLUS LUTEUS)
}

\author{
Miroslava Ivanova $^{1}$, Lilko Dospatliev ${ }^{2} \S$ \\ ${ }^{1}$ Department of Informatics and Mathematics \\ Trakia University \\ Stara Zagora, 6000, BULGARIA \\ ${ }^{2}$ Department of Pharmacology, Animal Physiology \\ and Physiological Chemistry \\ Trakia University \\ Stara Zagora, 6000, BULGARIA
}

\begin{abstract}
The aims of this work were to determine heavy metals ( $\mathrm{Pb}, \mathrm{Cd}, \mathrm{Co}$, $\mathrm{Cu}, \mathrm{Mn}, \mathrm{Zn}$ and $\mathrm{Fe}$ ) contents in the wild edible mushroom Suillus luteus growing in the Batak Mountain, Bulgaria and to identify the relationship between Fe and the other elements using ordinary least squares multiple linear regression model. Quantitative determination of the concentration of the studied heavy metals was carried out in mineralized samples by Perkin Elmer AAnalyst 800 atomic absorption spectrometer with deuterium background corrector. All statistical computing, analysis and all charts were performed with the statistical software $\mathrm{R}$ program. We received an ordinary least squares multiple linear regression model showed that: $\mathrm{Zn}, \mathrm{Mn}, \mathrm{Cu}$, Co and $\mathrm{Pb}$ increase by $1 \%$, the effect of this increase would result in an increase in Fe by $2.15 \%$ on the average; if $\mathrm{Cd}$ decreases by $1 \%$, the effect of this decrease would result in an decrease in Fe by $31 \%$.
\end{abstract}

AMS Subject Classification: 62J05, 62P10

Key Words: linear regression model, ordinary least squares, heavy metals, mushroom Suillus luteus

Received: June 25, 2019

(c) 2019 Academic Publications

${ }^{\S}$ Correspondence author 


\section{Introduction}

According to the Food and Agriculture Organization of the United Nations, 1350 species are considered as edible mushrooms. There is no doubt that mushrooms play an important role in human diet, especially in regions with deep and old tradition of mushrooming. In many countries, picking wild grown mushrooms is a habitual activity; for example in 2014, 5212 tonnes forestgrowing mushrooms purchased from pickers, worth more than 16 million euro, were reported in Poland. China is the leading producer, user and exporter of wild edible mushrooms fin the world (including wild-growing and cultivated mushrooms). According to FAO, Bulgaria is Europe's leading exporter of mushrooms. The edible mushrooms are an increasing part of human diet. For example, in the Bulgaria, annual per capita consumption is over $6 \mathrm{~kg}$ of fresh mushrooms (see [4]).

Wild-growing saprobic and symbiotic mushrooms may accumulate considerable amounts of metallic elements and metalloids in their fruiting bodies due to specificities in their physiology. The known essential micronutrient minerals are iron, zinc, selenium, manganese, cobalt and copper. They play an important role in the catalytic processes within the enzyme system that includes a wide range of enzyme activities associated with metabolic, endocrine and immune systems. Living organisms require some heavy metals, including iron, cobalt, copper, manganese, chromium and zinc. Excessive levels of these metals, however, can be detrimental to human health. Lead and cadmium are toxic and have no beneficial effects on organisms. Furthermore, deficiency or imbalance of essential or non-essential minerals above threshold concentration levels confers a risk of disease development. Therefore, the adequate and accurate food composition data are essential for estimating the adequacy of intake of essential nutrients and assessing the risk from toxic metals (see [1], [5]).

The aims of this article were to determine heavy metals $(\mathrm{Pb}, \mathrm{Cd}, \mathrm{Co}, \mathrm{Cu}$, $\mathrm{Mn}, \mathrm{Zn}$ and Fe) contents in wild edible mushroom Suillus luteus growing in the Batak Mountain, Bulgaria and to identify the relationship between Fe and the other elements using ordinary least squares multiple linear regression model.

Iron was chosen because it is considered to be the most important metal involved in the transformation of the energy required for synthesis and other life processes in the cells. Also, the iron content in mushrooms ranges from 10 to $1000 \mathrm{mg} \mathrm{kg}^{-1}$ dry matter in a sufficient amount of $50-75 \mathrm{mg} \mathrm{kg}^{-1}$ (see [2]). 


\section{Materials and methods}

\subsection{Plant material}

Mushroom samples were collected in 2018 from the Batak Mountain, Bulgaria by the authors themselves. The Batak Mountain is located in western Rhodopes. Its western border is defined by the Chepinska river, the southern border - by Dospatska river and Dospat dam, the eastern border - by Vacha river and the northern border - by the Thracian Plane (GPS41 $46^{\prime} 02.6^{\prime \prime} \mathrm{N} 24^{\circ} 08^{\prime}$ $\left.48.4^{\prime \prime} \mathrm{E}\right)$. The region is industry-free and is characterized with forests, land and low buildings.

\subsection{Chemical analysis methods}

Quantitative determination of the concentration of the studied heavy metals $(\mathrm{Pb}, \mathrm{Cd}, \mathrm{Co}, \mathrm{Cu}, \mathrm{Mn}, \mathrm{Zn}$ and $\mathrm{Fe})$ was carried out in the mineralized samples by Perkin Elmer AAnalyst 800 atomic absorption spectrometer with deuterium background corrector.

\subsection{Digestion procedures}

Multiwave 3000 closed vessel microwave system (maximum power was $1400 \mathrm{~W}$, and the maximum pressure in Teflon vessels - 40 bar) was used in this study mushroom samples $(0.25 \mathrm{~g})$ were digested with $6 \mathrm{~mL}$ of $\mathrm{HNO}_{3}(65 \%)$ and 1 $\mathrm{mL}$ of $\mathrm{H}_{2} \mathrm{O}_{2}(30 \%)$ in microwave digestion system for $23 \mathrm{~min}$ and diluted to 25 $\mathrm{mL}$ with deionized water. A blank digest was carried out in the same way. All sample solutions were clear.

\subsection{Statistical analysis}

\subsubsection{Statistical Software}

All statistical computing, analysis and all charts were performed with the statistical software R program Version 3.5.1.

\subsubsection{Shapiro-Wilk test}

The Shapiro-Wilk test is a test for normal distribution exhibiting high power, leading to good results even with a small number of observations. In contrast 
to other comparison tests the Shapiro-Wilk test is only applicable to check for normality. The null-hypothesis $\left(\mathrm{H}_{0}\right)$ : the population is normally distributed. The test statistic is (see [6]):

$$
W=\frac{\left(\sum_{i=2}^{n} a_{i} y_{i}\right)^{2}}{\sum_{i=1}^{n}\left(x_{i}-\bar{y}\right)^{2}},
$$

where $n$ - number of observations, $y_{i}$ - values of the ordered sample, $a_{i}$ - tabulated coefficient.

\subsubsection{Durbin-Watson test}

The Durbin-Watson test statistic tests the null hypothesis that the residuals from an ordinary least-squares regression are not autocorrelated. The DurbinWatson statistic ranges in value from 0 to 4 . A value near 2 indicates nonautocorrelation; a value toward 0 indicates positive autocorrelation; a value toward 4 indicates negative autocorrelation. The test statistic is (see [3]):

$$
d=\frac{\sum_{t=2}^{n}\left(e_{t}-e_{t-1}\right)^{2}}{\sum_{t=1}^{n} e_{t}^{2}}
$$

where $e_{t}$ is the residual residual associated with the observation at time $t$ and $n$ is the number of observations.

Because of the dependence of any computed Durbin-Watson value on the associated data matrix, exact critical values of the Durbin-Watson statistic are not tabulated for all possible cases. Instead, Durbin and Watson established upper (DU) and lower bounds (DL) for the critical values. Typically, tabulated bounds are used to test the hypothesis of zero autocorrelation against the alternative of positive first-order autocorrelation, since positive autocorrelation is seen much more frequently in practice than negative autocorrelation (see [8]).

\subsubsection{F-test}

The F-test for linear regression tests whether any of the independent variables in a multiple linear regression model are significant. The formula for F-test statistic is

$$
F=\frac{\text { explained variance }}{\text { unexplained variance }} \text {. }
$$

F-test is greater as: 
- distance between groups is greater or dispersion media groups around the general average is greater;

- groups are more homogeneous or error represented by scattering within the groups is less.

Thus, relatively high F's are strong arguments against $\mathrm{H}_{0}$ (null hypothesis). $\mathrm{P}$-value is the probability of obtaining a value of $\mathrm{F}$ which is at least as great as that observed by us if $\mathrm{H}_{0}$ were true. Therefore, the smaller the p-value the chance that $\mathrm{H}_{0}$ to be fair are lower. For p-value $<0.05$ to reject $\mathrm{H}_{0}$ it is necessary the following condition:

$$
\begin{aligned}
F_{\text {calculat }} & \succ F_{\text {tabular }} \\
(\text { Fcalculated } & >\text { Ftabular }) .
\end{aligned}
$$

\subsubsection{Variance inflation factors}

Variance inflation factors (VIF) measure how much the variance of the estimated regression coefficients are inflated as compared to when the predictor variables are not linearly related. If VIF $>10$ there is an indication for multicollinearity to be present (see [9]).

\subsubsection{Model specification}

In econometrics, ordinary least squares (OLS) method is widely used to estimate the parameter of a linear regression model. OLS estimators minimize the sum of the squared errors (a difference between observed values and predicted values). The OLS estimator is consistent when the regressors are exogenous, and optimal in the class of linear unbiased estimators when the errors are homoscedastic and serially uncorrelated. Under these conditions, the method of OLS provides minimum-variance mean-unbiased estimation when the errors have finite variances. Under the additional assumption that the errors are normally distributed, OLS is the maximum likelihood estimator.

In this article we used OLS multiple linear regression model to identify the dependences of heavy metals in wild edible mushroom Suillus luteus. The long-run functions are specified as follows:

$$
F e=f(Z n, M n, C u, C o, C d, P b) .
$$

From the point of view of multiple linear regression, the constructed models must satisfy the following assumptions: linear relationship, multivariate nor- 
mality, no or little multicollinearity, no autocorrelation and homoscedasticity (see $[9])$.

\section{Results and discussion}

Concentrations of seven heavy metals ( $\mathrm{Pb}, \mathrm{Cd}, \mathrm{Co}, \mathrm{Cu}, \mathrm{Mn}, \mathrm{Zn}$ and $\mathrm{Fe}$ ) have been determined in this study. The heavy metal contents of the species depend on the ability of the species to extract elements from the substrate, and on the selective uptake and deposition of elements in tissues. The results obtained in the current study, indicated that $\mathrm{Pb}, \mathrm{Cd}, \mathrm{Co}, \mathrm{Cu}, \mathrm{Mn}, \mathrm{Zn}$ and $\mathrm{Fe}$ content of the investigated mushroom samples were comparable with those reported in the literature (Table 1) (see [1], [4], [5]). The averages of $\mathrm{Pb}, \mathrm{Cd}, \mathrm{Co}, \mathrm{Cu}, \mathrm{Mn}, \mathrm{Zn}$ and Fe present in the studied wild mushrooms were far below the limits set by the WHO (see [7]).

Descriptive statistics was used to make a preliminary analysis of the database (Table 1). It was concluded that data for $\mathrm{Pb}, \mathrm{Cd}, \mathrm{Co}, \mathrm{Mn}, \mathrm{Zn}$ were fairly symmetrical because the skewness was between -0.5 and 0.5 , and data for Fe and $\mathrm{Cu}$ were negatively skewed (skewness between -1 and -0.5 ). Co and Fe data can be considered homogeneous. From the Shapiro-Wilk Test, the p-value $>0.05$ suggested that the distribution of the data was not significantly different from normal. In other words, normality could be assumed.

\subsection{Econometric model for $\mathrm{Fe}$}

In an explicit and econometric form, the long-run function of Fe can be stated as:

$$
F e=a_{0}+a_{1} Z n+a_{2} M n+a_{3} C u+a_{4} C o+a_{6} C d+a_{7} P b .
$$

For econometric modelling of the variables included in this study factor Fe was considered as a resultant factor and $\mathrm{Zn}, \mathrm{Mn}, \mathrm{Cu}, \mathrm{Co}, \mathrm{Cd}$ and $\mathrm{Pb}$ : as independent factors (Table 2).

At the significance level, four out of seven regression coefficients were statistically significant. The econometric analysis of the model highlighted the fact that the relationship between dependent and independent factors was rather strong (Table 2): the correlation coefficient was $\mathrm{R}=0.986$ and the determination coefficient (Multiple R-squared) was 0.971 or roughly $97 \%$ of the variance found in the response variable $(\mathrm{Fe})$ can be explained by predictor variables. The Durbin-Watson test for verifying the autocorrelation of random variable showed that the model obtained after data processing was correct (test statistic 
Table 1: Descriptive statistics of the results for $\mathrm{Pb}, \mathrm{Cd}, \mathrm{Co}, \mathrm{Cu}, \mathrm{Mn}$, $\mathrm{Zn}$ and Fe concentrations in Suillus luteus mushroom $(n=15)$

\begin{tabular}{llllllll}
\hline & $\mathrm{Pb}$ & $\mathrm{Cd}$ & $\mathrm{Co}$ & $\mathrm{Cu}$ & $\mathrm{Mn}$ & $\mathrm{Zn}$ & $\mathrm{Fe}$ \\
\hline Mean & 7.96 & 0.97 & 1.03 & 6.12 & 14.46 & 78.56 & 84.95 \\
St. Errar & 0.38 & 0.03 & 0.02 & 0.49 & 0.44 & 1.09 & 1.82 \\
Median & 7.91 & 0.95 & 1.03 & 6.75 & 14.08 & 77.90 & 86.84 \\
Std. Dev. & 1.47 & 0.11 & 0.08 & 1.88 & 1.69 & 4.22 & 7.04 \\
Sample Variance & 2.16 & 0.01 & 0.01 & 3.54 & 2.86 & 17.77 & 49.57 \\
Kurtosis & -1.15 & -0.82 & -1.23 & -0.58 & -1.21 & -0.92 & -0.34 \\
Skewness & 0.01 & 0.24 & -0.39 & -0.57 & 0.03 & 0.40 & -0.78 \\
Range & 4.85 & 0.36 & 0.24 & 5.86 & 5.23 & 12.06 & 22.03 \\
Minimum & 5.54 & 0.79 & 0.89 & 3.03 & 11.62 & 73.16 & 71.96 \\
Maximum & 10.40 & 1.15 & 1.13 & 8.89 & 16.86 & 85.21 & 93.99 \\
Sum & 119.36 & 14.59 & 15.48 & 91.82 & 216.85 & 1178.45 & 1274.21 \\
Count & 15.00 & 15.00 & 15.00 & 15.00 & 15.00 & 15.00 & 15.00 \\
Conf. Level (95\%) & 0.81 & 0.06 & 0.05 & 1.04 & 0.94 & 2.33 & 3.90 \\
Homogeneous coefficient $(\%)$ & 18.45 & 10.91 & 8.07 & 30.72 & 11.70 & 5.37 & 8.29 \\
Shapiro-Wilk Test & 0.950 & 0.949 & 0.892 & 0.897 & 0.938 & 0.912 & 0.896 \\
p-value & 0.532 & 0.518 & 0.072 & 0.085 & 0.359 & 0.144 & 0.081 \\
\hline
\end{tabular}


Table 2: Econometric modeling for Fe

\begin{tabular}{lllll}
\hline Coefficient & Estimate & Std. Error & t value & $\operatorname{Pr}(>|t|)$ \\
\hline$a_{0}$ & 46.758 & 16.783 & 2.786 & $0.024^{*}$ \\
$a_{1}$ & 0.460 & 0.142 & 3.247 & $0.012^{*}$ \\
$a_{2}$ & 1.280 & 0.331 & 3.862 & $0.005^{* *}$ \\
$a_{3}$ & 0.481 & 0.282 & 1.707 & 0.126 \\
$a_{4}$ & 8.195 & 5.915 & 1.385 & 0.203 \\
$a_{5}$ & -31.245 & 6.445 & -4.848 & $0.001^{* *}$ \\
$a_{6}$ & 0.318 & 0.395 & 0.804 & 0.445
\end{tabular}

Residual standard error: 1.574

Multiple R-squared: 0.971

Adjusted R-squared: 0.951

F-statistic: $45.330\left(\mathrm{p}\right.$-value $\left.=9.545 e^{-06}\right)$

Durbin-Watson stat: $2.426(\mathrm{p}$-value $=0.5055)$

Signif. codes: 0 '***, $0.001^{\text {'**' }} 0.01$ '*' 0.05 '? 0.1 ', 1

value $=2.426$ was greater than $\mathrm{dU}=2.244$, then the null hypothesis was not reject [7]). The calculated values of the Fisher's F-test (F) of the econometric model indicated the higher relevance of the model $(\mathrm{F}=45.330, \mathrm{p}$-value $=$ $\left.9.545 \mathrm{e}^{-06}\right)$. Tabular value given by test was 4.48 for a probability of $0.05(5 \%)$ [10], which means that the resulting equation was: $\mathrm{F}$ calculated $>\mathrm{F}$ tabular. So the null hypothesis $\left(\mathrm{H}_{0}\right)$ was rejected and the variances included in the study differed significantly between them. The VIF values for the explanatory variables Zn, Mn, Cu, Co, Cd and Pb were: 2.016002, 1.774993, 1.584088, 1.371218, 2.639673 and 1.902754, respectively. Since there were no values exceeding 10, it was concluded that the model was free from multicollinearity.

Thus, we have the following equation for the dependent variable Fe:

$$
\begin{aligned}
F e=46.758 & +0.460 Z n+1.280 M n+0.481 C u+8.195 C o \\
& -31.245 C d+0.318 P b .
\end{aligned}
$$

According to (1), a direct influence, increasing the resultant factor Fe, was found out for the factors $\mathrm{Zn}, \mathrm{Mn}, \mathrm{Cu}, \mathrm{Co}$ and $\mathrm{Pb}$. Classification ranges given by model coefficients are presented in Table 3. Calculations were performed with a probability of $90 \%$ and respectively $95 \%$. Zn and $\mathrm{Cd}$ variables ranges were relevant in both cases of the evaluation. 
Table 3: Coefficient confidence intervals

\begin{tabular}{llllll}
\hline \multirow{2}{*}{ Coefficient } & \multirow{2}{*}{ Estimate } & \multicolumn{2}{c}{$90 \%$} & \multicolumn{2}{c}{$95 \%$} \\
& & lower & upper & lower & upper \\
\hline$a_{0}$ & 46.758 & 15.549 & 77.966 & 8.057 & 85.459 \\
$a_{1}$ & 0.460 & 0.197 & 0.724 & 0.133 & 0.787 \\
$a_{2}$ & 1.280 & 0.663 & 1.895 & 0.516 & 2.043 \\
$a_{3}$ & 0.481 & -0.043 & 1.004 & -0.169 & 1.129 \\
$a_{4}$ & 8.195 & -2.805 & 19.195 & -5.446 & 21.836 \\
$a_{5}$ & -31.245 & -43.229 & -46.107 & 8.057 & -16.383 \\
$a_{6}$ & 0.318 & -0.417 & 1.053 & -0.594 & 1.229 \\
\hline
\end{tabular}

Figure 1 depicts graphically the validity of regressors, i.e. variable plots and plots of residuals versus each regressor.

Figure 2 depicts graphically the differences in the calculation of actual data vs. predicted data from the model, which indicate the ability to perform some calculations for different values of the variable Fe of the factors included in the presented model.

\section{Conclusion}

Results of the studied area showed that the selected metals concentrations were below the safe limits of WHO/FAO set for edible mushrooms and for foodstuffs. This could be attributed to the lack of anthropogenic input like mining and industry and low-scale agricultural activities. From the obtained concentrations of heavy metals it could be concluded that the locality Batak mountain, Bulgaria is an ecologically clean area, very suitable for collecting wild edible mushrooms for daily rations. Based on the obtained econometric model, the following interpretations for Fe contents in the wild edible mushroom Suillus luteus growing in the Batak Mountain, Bulgaria could be made:

- If $\mathrm{Zn}, \mathrm{Mn}, \mathrm{Cu}, \mathrm{Co}$ and $\mathrm{Pb}$ increase by $1 \%$, the effect of this increase would result in an increase in Fe by $2.15 \%$ on the average;

- If $\mathrm{Cd}$ decreases by $1 \%$, the effect of this decrease would result in an decrease in Fe by $31 \%$. 


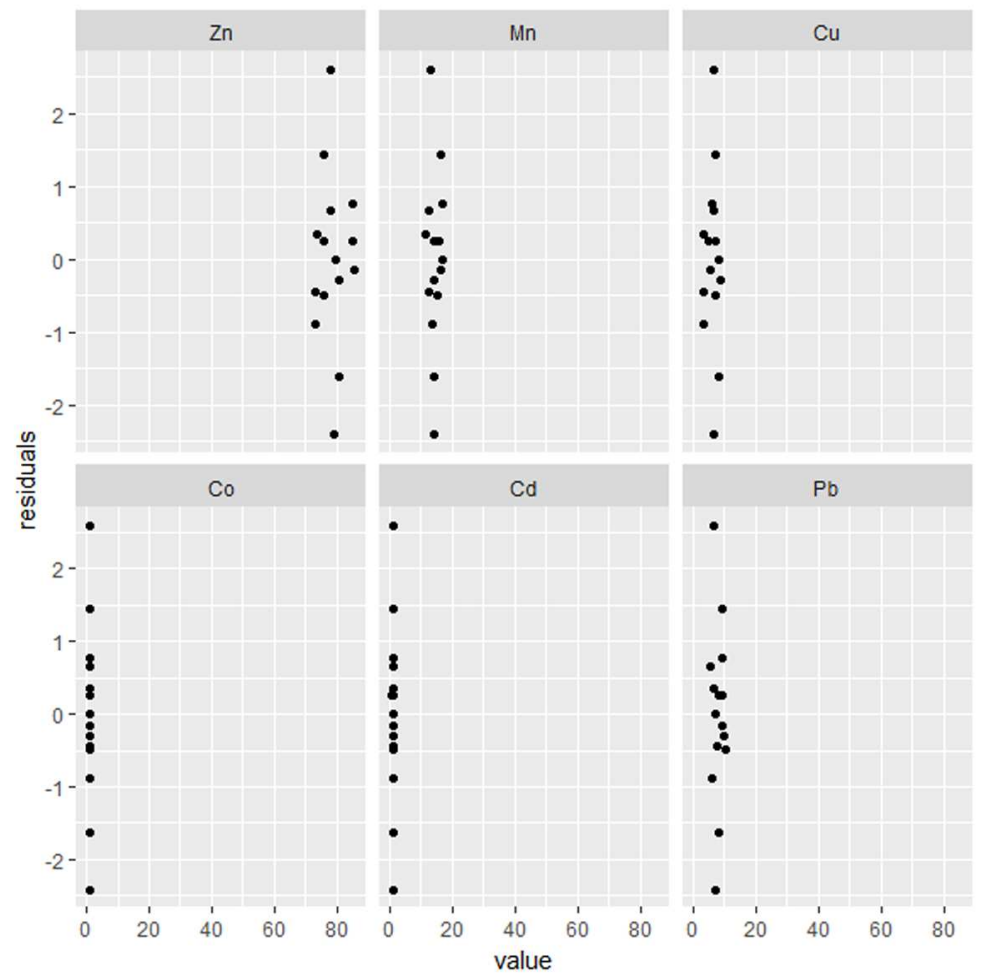

Figure 1: Plots of the residuals versus each regressor

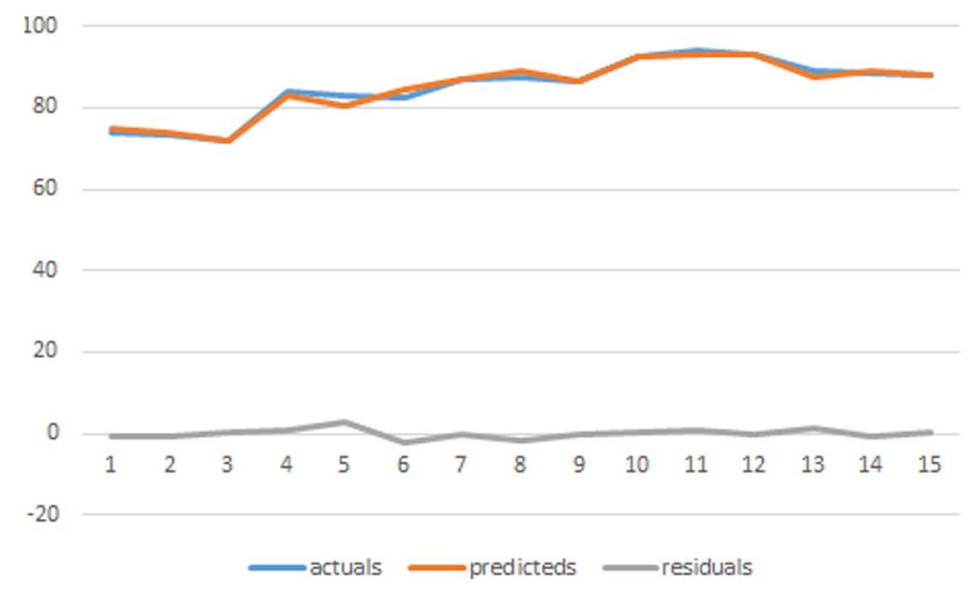

Figure 2: Differences of actual data vs. predicted data from the model of $\mathrm{Fe}$ 


\section{References}

[1] J. Falandysz, A. Sapkota, A. Dryżałowska, M. Mędyk, X. Feng, Analysis of some metallic elements and metalloids composition and relationships in parasol mushroom Macrolepiota procera, Environ. Sci. Pollut. R., 24, No 18 (2017), 15528-15537; doi: 10.1007/s11356-017-9136-9.

[2] C.D. Foy, R.L. Chanry, M.C. White, Morphology of metal toxicity in plants, Annu. Rev. Plant Physiol., 29 (1978), 511-566.

[3] D. Gujarati, Basic Econometrics, McGraw-Hill, Boston-Singapore, etc. (2003).

[4] P. Kalač, A review of chemical composition and nutritional value of wildgrowing and cultivated mushrooms, J. Sci. Food Agric., 93 (2013), 209-218.

[5] P. Rzymski, P. Klimaszyk, Is the Yellow Knight mushroom edible or not? A systematic review and critical viewpoints on the toxicity of Tricholoma equestre, Compr. Rev. Food Sci. Food Saf., 17 (2018), 1309-1324.

[6] S.S. Shapiro, M.B. Wilk, An analysis of variance test for normality (complete samples), Biometrika, 52 (1965), 591-611.

[7] WHO, World Health Organization Evaluation of Certain Foods Additives and Contaminants (Twenty-Six Report of the Joint FAO/WHO Expert Committee on Food Additives), WHO Library Cataloguing-in-Publication Data, WHO: Geneva, Switzerland (1982).

[8] https://www3.nd.edu/ wevans1/econ30331/Durbin_Watson_tables.pdf

[9] https://www.statisticssolutions.com/wp-content/uploads/wp-post-to-pdfenhanced-cache/1/assumptions-of-multiple-linear-regression.pdf

[10] http://www.stat.purdue.edu/ jtroisi/STAT350Spring2015/tables/ FTable.pdf 
